\title{
Allergic Basal Deciduitis as a Reason of Recurrent Antenatal Fetal Death
}

\author{
Yevgeniy Kamyshanskiy(D, Olga Kostyleva(D), Leila Stabayeva, (D) Gulnazira Imanbaeva(D), Raihan Nygyzbaeva(D), \\ Evgeniy Kotov, Denis Kossitsyn
}

Department of Pathology, Karaganda Medical University, Karaganda, Kazakhstan

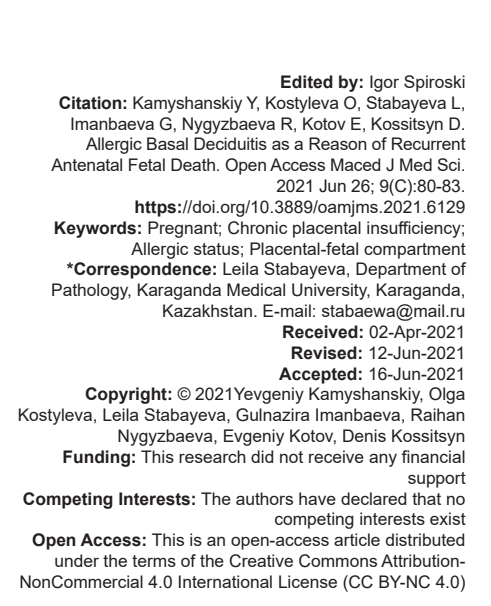

Abstract

BACKGROUND: Allergic diseases of pregnant women are associated with chronic placental insufficiency and the development of immunopathological conditions of unknown etiology in a child in postnatal life. Pregnancy with bronchial asthma is often complicated by intrauterine growth retardation, preeclampsia, and antenatal fetal death.

AIM: The objective was to present a clinical case of recurrent antenatal fetal death in the third trimester in women with bronchial asthma under controlled course.

CASE REPORT: Pregnancy proceeded without clinical signs of exacerbation of bronchial asthma and allergic status. However, chronic inflammation with eosinophilia in the intervillous space and the basal lamina was revealed in the placenta tissue. Eosinophilia of the intervillous area was accompanied by obliteration of the intervillous area by fibrin deposits.

CONCLUSION: We suppose that immunological inflammation at the fetoplacental unit level can occur regardless of the mother's allergic status. Moreover, it is likely that the objective state of the mother in the presence of an allergic disease does not reflect the presence/absence of an immunological process in the placenta, as the immunologica inflammatory process can develop in different compartments (at the level of the mother's body and the placental-fetal compartment) with varying degrees of severity.

\section{Introduction}

An urgent problem for obstetricians and gynecologists is the growing number of allergic conditions, which occupy an important place in the structure of morbidity in women of childbearing age, including pregnant women. In addition, an exacerbation of an existing allergic disease often occurs during pregnancy, which can lead to hospitalization and even maternal and perinatal morbidity and mortality. At the same time, the possibility of intrauterine allergic sensitization of the fetus under the influence of the maternal immune system and its relationship with the degree of clinical manifestations in a pregnant woman remains unclear.

It is customary in classical allergology to call immunoglobulin E (lgE)-mediated allergy (the I $^{\text {st }}$ type of immunological reactions) as true allergy. IgE antibodies are involved in allergic processes such as anaphylaxis, allergic rhinitis, asthma, and atopic dermatitis and are also associated with protection against parasitic reactions [1]. $\lg \mathrm{E}$ is considered the only class of antibodies that cross the placental barrier from mother to child. Hence, it was found that $\lg \mathrm{E}$ is determined in the chorionic villi already from the $12^{\text {th }}$ week of pregnancy [2]. There is an assumption that the transition of maternal IgE to the placenta, on the one hand, determines the absence of an allergic reaction between fetal and maternal antigens, on the other hand, the transition of sensitized IgE antibodies can lead to the development of a congenital allergic status of the fetus.

Bronchial asthma is the most common allergic respiratory disorder complicating pregnancy, affecting one in eight pregnant women [3]. Uncontrolled bronchial asthma in pregnant women is associated with an increased risk of unfavorable maternal and perinatal outcomes: Preeclampsia, gestational diabetes, cesarean section, preterm birth, as well as low birth weight, lower Apgar scores of the newborn, chorioamnionitis, and intraventricular hemorrhage/neonatal mortality [4], [5], [6], [7], [8].

The objective was to present a clinical case of recurrent antenatal fetal death in the third trimester in women with bronchial asthma under controlled course.

\section{Case Report}

Pregnant A., 31 years old, third pregnancy. Complicated obstetric history: The first pregnancy in 
2012 - early miscarriage; the second pregnancy in 2013 ended at 28 weeks by the delivery of a dead premature fetus. The study of the placenta diagnosed chronic lymphohistiocytic basal deciduitis and intervillositis with eosinophilia.

In 2015, pregnancy at 11 weeks and 18 weeks +4 days was complicated by threatening spontaneous abortion and moderate chronic anemia. Pregnancy proceeded without clinical signs of bronchial asthma and allergic status exacerbation.

The patient was admitted to the emergency room with complaints of lack of fetal movement at 31 weeks of gestation +5 days. The performed ultrasound examination showed antenatal fetal death. A dead fetus was born, weighing $1700 \mathrm{~g}, 43 \mathrm{~cm}$ long by induction with Mifepristonum.

The placenta was fixed in $4 \%$ neutral buffered formalin followed by standardized notching, marking of representative diagnostically significant fragments of the placenta [9]. Macroscopic and histological examination of the placenta was carried out in accordance with Vogel principles [10], [11]. The histological criteria for the development and maturation of villi were the degree of branching, differentiation of the stroma, vascularization, and formation of syncytiocapillary membranes [12]. Table 1 shows the main clinical and morphological data of the placenta and fetus.

The article presents a clinical case of recurrent antenatal fetal death in women with bronchial asthma under controlled course. We believe that in this case, recurrent antenatal fetal asphyxia could be caused by immunological inflammation with an allergic component

Table 1: Clinical and morphological data of the placenta and fetus

\begin{tabular}{ll}
\hline Criteria & Parameters \\
\hline Gestational age & $31+5$ \\
Weight, g & 266 \\
Morphological characteristics of & the placenta \\
\multicolumn{1}{l}{ Placenta maturity } & Structural acceleration of placental development for \\
& gestational age \\
Stem villi & $10 \%$ \\
Intermediate mature & $35 \%$ \\
Intermediate immature & $11 \%$ \\
Terminal villi & $44 \%$ \\
Features of the & norm \\
umbilical cord & \\
Amniotic water amount & norm \\
Inflammatory changes & Acute necrotizing deciduitis with an immune component \\
Deciduitis & in the form of plasmacytic and eosinophilic infiltration \\
& Chronic lymphohistiocytic intervillositis of severe degree \\
Intervillositis & with eosinophilia \\
& Chronic lymphocytic villitis of severe degree \\
Villitis & Obliterating angiopathy of large vessels \\
Vasculopathy & Chorionic villus stromal sclerosis \\
Obliterating angiopathy & \\
Fibromuscular sclerosis & Regional infarctions of the placenta in the stage of \\
Circulatory disorders & organization \\
Infarctions & Violation of blood circulation in the intervillous \\
& space: Large-focal fibrin deposits and hemorrhages \\
Hematomas & with the formation of hematomas \\
& \\
Clinical data of the fetus & 1700 \\
Weight, g & 43,0 \\
Height, cm & + \\
Apgar & + \\
Antenatal asphyxia & \\
\hline
\end{tabular}

at the fetoplacental unit level, the degree of which did not correlate with the severity of clinical manifestations of bronchial asthma in pregnant woman.

Histological study of the placenta revealed structural acceleration for gestational age, partial, and complete obliteration of the lumen of large vessels, thickening of the chorionic villus stroma with lymphoid infiltration, fibrin deposits with obliteration of the intervillous space, as well as eosinophilic inflammatory infiltrate in the foci of basal lamina necrosis and intervillous area (Figure 1).

\section{Discussion}

Previously published works have shown that chronic inflammatory lesions of the placenta represent a heterogeneous group of cellular infiltrations by infectious, alloimmune, and unexplained genesis, occurring in different parts of the placenta [13], [14], [15], [16], [17]. Chronic villitis and intervillositis are defined as mixed lymphocytic and histiocytic infiltration that disrupts the syncytiotrophoblastic barrier. Maternal lymphocytes and fetal histiocytes can be present in the intervillous area in infectious, immunological, and hypoxic lesions.

The peculiarities of the morphology of the placenta in this clinical case are pathognomonic signs of a chronic form of inflammation with a predominance of the eosinophilic cellular component. As shown in the previous studies [18], [19], [20], eosinophilic cell infiltrate, which is often found in connection with allergic diseases in various organs, is very rarely seen as a component of the inflammatory infiltrate in the study of the placenta.

There are literary data of an association between the action of an allergen in the fetal period and a late predisposition to asthma and allergies [21], [22], [23]. IgE has been identified on macrophage-like cells in the villi of the human placenta, regardless of serum IgE levels, and maternal allergic status [24]. The presence of maternal lgE in the placenta from the second trimester of pregnancy, independent of maternal allergy or plasma IgE levels, may affect the outcome of pregnancy [25], [26].

The simultaneous presence of maternal lgE and low concentration of allergens can lead to IgE-mediated antigenic focusing on fetal antigen-presenting cells [27], [28]. IgE bound to FceRI on antigen-presenting cells serves as an allergen focusing structures and increases the antigen-presenting ability of low allergen concentration to allergen-specific T-cells [28]. Binding of allergens and $\operatorname{lgE}$ in the placenta can also lead to eosinophilia, local production of cytokines, and the release of proinflammatory cytokines and chemokines within the ovum is the leading cause of fetoplacental unit damage. 


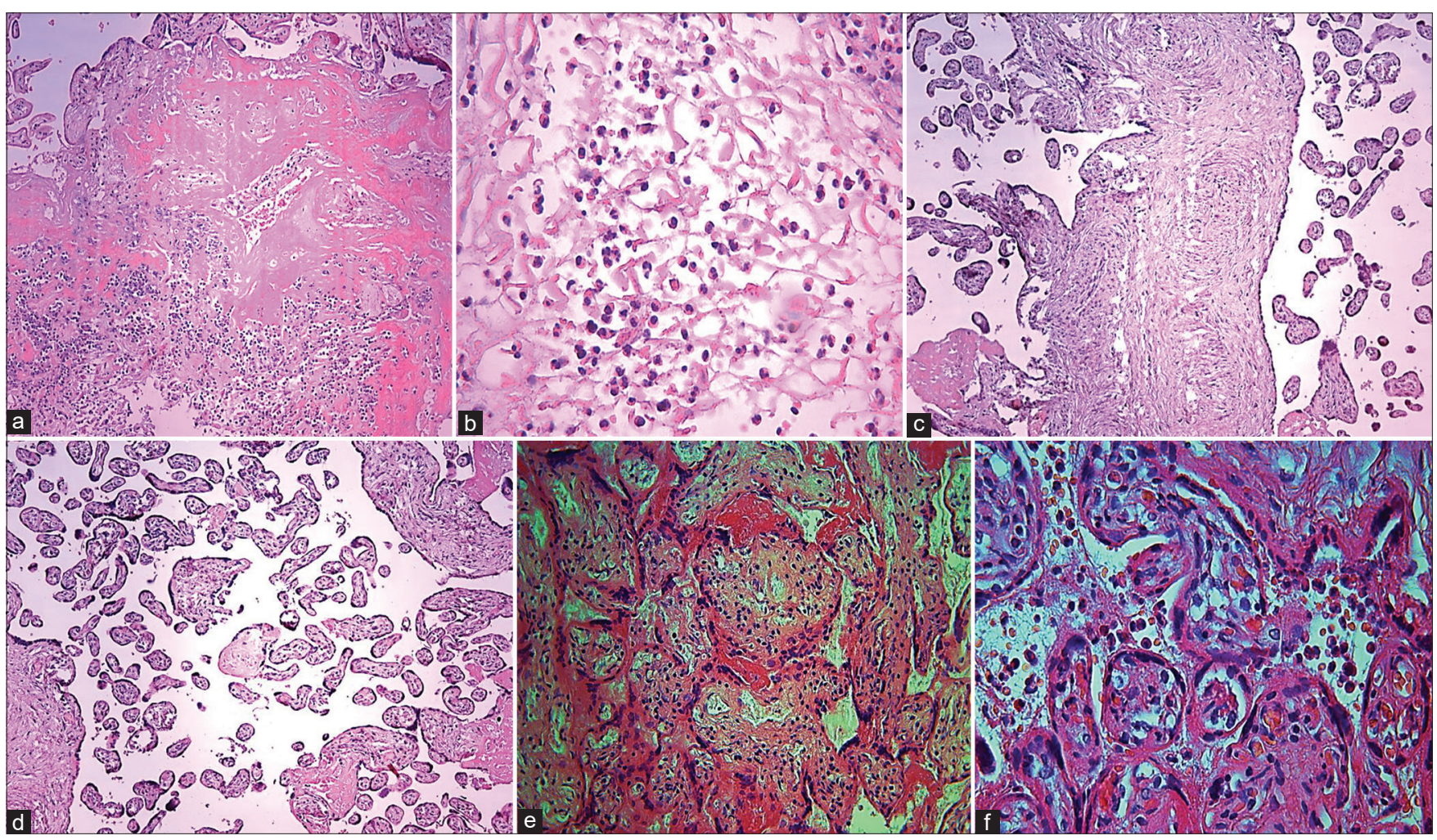

Figure 1: (a) Foci of necrosis (single arrow) and inflammatory cellular infiltrate (double arrow) in the tissue of the basal plate. Staining Hematoxylin and eosin (b) Inflammatory infiltrate in foci of necrosis of the basal lamina: Eosinophils (arrow), plasma cells (arrowhead). Staining: Hematoxylin and eosin (c) Partial and complete obliteration of the lumen of large vessels (obliterating angiopathy). Staining: Hematoxylin and eosin (d) Structural acceleration of chorionic villi development: Predominance of terminal villi (arrows). Staining: Hematoxylin and eosin (e) Compaction of the chorionic villi stroma with lymphoid infiltration (arrows); fibrin deposits with obliteration of the intervillous area (arrowhead). Staining: Hematoxylin and eosin (f) Inflammatory cellular infiltrate in the intervillous area: Eosinophils and lymphoid cells. Staining: Hematoxylin and eosin

\section{Conclusion}

We have shown that in the case described above, there is a discrepancy between the clinical data (persistent course of bronchial asthma and controlled in the remission stage) and the morphological picture of the placenta, which is associated with severe inflammation with a predominance of the eosinophilic cellular component.

In the described case of recurrent antenatal fetal death, the inflammatory process in the placenta could have an immunological and allergic mechanism of development due to the $\mathrm{IgE}$ associated antigenantibody reaction. It is known that $\mathrm{IgE}$ is present on the macrophages of the chorionic villi in normal and pathological conditions, the origin is the $\operatorname{lgE}$ of the "mother," not the fetus, and appears in the placenta at least from the second trimester of pregnancy. The biological role of IgE in the stroma of chorionic villi is not known, but it has been shown that this IgE may be allergen-specific. The binding of allergens and $\lg E$ in the placenta can lead to the local production of cytokines, which can affect the development of the immune system of the developing fetus and thereby provoke the development and predisposition of allergic reactions in post-natal life.
We suppose that immunological inflammation at the fetoplacental unit level can occur regardless of the mother's allergic status. Moreover, it is likely that the objective state of the mother in the presence of an allergic disease does not reflect the presence/absence of an immunological process in the placenta, as the immunological inflammatory process can develop in different compartments (at the level of the mother's body and the placental-fetal compartment) with varying degrees of severity. However, this opinion remains open and requires additional scientific researches.

\section{References}

1. Gould HJ, Sutton BJ, Beavil AJ, Beavil RL, McCloskey N Coker HA, et al. The biology of IGE and the basis of allergic disease. Annu Rev Immunol. 2003;21:579-28. https://doi. org/10.1146/annurev.immunol.21.120601.141103 PMid:12500981

2. Punnonen J, Aversa GG, Vandekerckhove B, Roncarolo MG, de Vries JE. Induction of isotype switching and Ig production by CD5+ and CD10+ human fetal B cells. J Immunol. 1992;148(11):3398-404.

PMid:1375243

3. Bain E, Pierides $\mathrm{KL}$, Clifton VL, Hodyl NA, Stark MJ. 
Interventions for managing asthma in pregnancy. Cochrane Database Syst Rev. 2014;2014(10):CD010660. https://doi. org/10.1002/14651858.cd010660.pub2

\section{PMid:25331331}

4. Sheiner E, Mazor M, Levy A, Wiznitzer A, Bashiri A. Pregnancy outcome of asthmatic patients: A population-based study. J Matern Fetal Neonatal Med. 2005;18(4):237-40. https://doi. org/10.1080/14767050500260616

PMid:16318973

5. Alcazar MA, Nusken E, Nuesken K. Programming intrauterine deficiency. In: Monatsschrift Kinderheilkunde. Vol. 164. Berlin, Germany: Springer; 2016. p. 106. https://doi.org/10.1007/ s00112-015-3420-x

6. Murphy VE, Gibson PG, Smith R, Clifton VL. Asthma during pregnancy: Mechanisms and treatment implications. Eur Resp J. 2005;25(4):731-50.

PMid:15802351

7. Prada JA, Tsang RC. Biological mechanisms of environmentally induced causes of IUGR. Eur J Clin Nutr. 1998;52(1):21-8. PMid:9511016

8. Liu S, Wen SW, Demissie K, Marcoux S, Kramer MS. Maternal asthma and pregnancy outcomes: A retrospective cohort study. Am J Obstet Gynecol. 2001;184(2):90-6. https://doi. org/10.1067/mob.2001.108073

\section{PMid:11174486}

9. Dudenhausen JW, Maier RF. Perinatal problems in multiple births. Dtsch Ärztebl Int. 2010;107(38):663-8.

PMid:20953254

10. Vogel M. Atlas der Morphologischen Plazentadiagnostik. $2^{\text {nd }}$ ed. Heidelberg: Springer-Verlag; 1996.

11. Vogel M, Kloppel G, Kreipe H, Remmele W. Pathologie der Plazenta: Spatschwangerschaft und fetoplazentare Einheit, Pathologie. Heidelberg: Springer-Verlag; 2013. p. 519. https:// doi.org/10.1007/978-3-642-04564-6_25

12. Benirschke K, Kaufmann P, Baergen R. Pathology of the Human Placenta. $5^{\text {th }}$ ed. New York: Springer; 2006.

13. Kapur P, Rakheja D, Gomez AM, Sheffield J, Sanchez P, Rogers BB. Characterization of inflammation in syphilitic villitis and in villitis of unknown etiology. Pediatr Dev Pathol. 2004;7(5):453-8. https://doi.org/10.1007/s10024-004-2124-3 PMid: 15547769

14. Myerson D, Parkin RK, Benirschke K, Tschetter CN, Hyde SR. The pathogenesis of villitis of unknown etiology: Analysis with a new conjoint immunohistochemistry-in situ hybridization procedure to identify maternal and fetal cells. Pediatr Dev Pathol. 2006;9(4):257-65. https://doi.org/10.2350/08-05-0103.1 PMid:16944988

15. Redline RW, Patterson P. Patterns of placental injury: Correlations with gestational age, placental weight, and clinical diagnoses. Arch Pathol Lab Med. 1994;118(7):698-701. PMid:8024402

16. Redline RW, Abramowsky CR. Clinical and pathologic aspects of recurrent placental villitis. Hum Pathol. 1985;16(7):727-31. https://doi.org/10.1016/s0046-8177(85)80159-3

PMid:4007849
17. Russell P, Atkinson K, Krishnan L. Recurrent reproductive failure due to severe placental villitis of unknown etiology. J Reprod Med. 1980;24(2):93-98.

PMid:7359507

18. Katzman PJ, Oble DA. Eosinophilic/T-cell chorionic vasculitis and chronic villitis involve regulatory $T$ cells and often occur together. Pediatr Dev Pathol. 2013;16(4):278-91. https://doi. org/10.2350/12-10-1258-oa.1

PMid:23600955

19. Katzman PJ, Li L, Wang N. Identification of fetal inflammatory cells in eosinophilic/T-cell chorionic vasculitis using fluorescent in situ hybridization. Pediatr Dev Pathol. 2015;18(4):305-9.

PMid:25756311

20. Jacques SM, Qureshi F, Kim CJ, Lee JH, Giorgadze T, Mittal P, et al. Eosinophilic/T-cell chorionic vasculitis: A clinicopathologic and immuno-histochemical study of 51 cases. Pediatr Dev Pathol. 2011;14(3):198-205. https://doi.org/10.2350/10-07-0867-oa.1 PMid:21050080

21. Chung EK, Miller RL, Wilson MT, McGeady SJ, Culhane JF. Antenatal risk factors, cytokines and the development of atopic disease in early childhood. Arch Dis Child Fetal Neonatal Ed. 2007;92(1):F68-73. https://doi.org/10.1136/adc.2006.106492 PMid: 17185433

22. Prescott SL, Clifton V. Asthma and pregnancy: Emerging evidence of epigenetic interactions in utero. Curr Opin Allergy Clin Immunol. 2009;9(5):417-26. https://doi.org/10.1097/ aci.0b013e328330634f

PMid:19652594

23. Kumar R. Prenatal factors and the development of asthma. Curr Opin Pediatr. 2008;20(6):682-7.

PMid:19005336

24. Joerink M, Rindsjö E, Stenius F, Alm J, Lilja G, Grönlund H, et al. Evidence for allergen-specific IgE of maternal origin in human placenta. Allergy. 2009;64(6):905-12. https://doi. org/10.1111/j.1398-9995.2009.01941.x

PMid:19220215

25. Rindsjo $E$, Varli $I H$, Ofori $M F$, Lundquist $M$, Holmlund $U$, Papadogiannakis $\mathrm{N}$, et al. Presence of $\mathrm{IgE}$ cells in human placenta is independent of malaria infection or chorioamnionitis. Clin Exp Immunol. 2006;144(2):204-11. https://doi. org/10.1111/j.1365-2249.2006.03055.x

PMid:16634792

26. Hanzlikova J, Ulcova-Gallova Z, Malkusova I, Sefrna F, Panzner P. TH1-TH2 response and the atopy risk in patients with reproduction failure. Am J Eprod Immunol. 2009;61(3):213-20. https://doi.org/10.1111/j.1600-0897.2009.00683.x PMid:19239423

27. Jones CA, Warner JA, Warner JO. Fetal swallowing of IgE. Lancet. 1998;351(9119):1859. https://doi.org/10.1016/ s0140-6736(05)78805-x PMid:9652674

28. Maurer D, Ebner C, Reininger B, Fiebiger E, Kraft D, Kinet JP, et al. The high affinity IgE receptor (Fc epsilon RI) mediates IgE-dependent allergen presentation. J Immunol. 1995;154(12):6285-90.

PMid:7759866 